\title{
SUSTAINABLE DEVELOPMENT AND THE GREAT SAGE-GROUSE
}

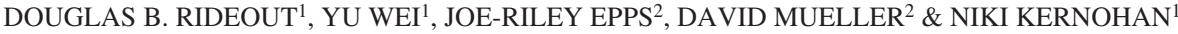 \\ ${ }^{1}$ WESTFIRE Research Centre, Department of Forest and Rangeland Stewardship, \\ Colorado State University, U.S.A. \\ ${ }^{2}$ Department of the Interior, Bureau of Land Management, U.S.A.
}

\begin{abstract}
The invasion of non-native grasses, pinyon-juniper encroachment, drought and climate change have resulted in larger, more intense fires in the western United States' sagebrush-steppe ecosystem. The U.S. Fish and Wildlife Service identified these factors as the primary threat to sagebrush obligate species, particularly the endemic greater sage-grouse. A large portion of primary sage-grouse conservation areas reside on the U.S. Department of the Interior federal lands. In 2015, the DOI issued Secretarial Order 3336 that directed the development of a comprehensive science-based strategy to reduce the threat of large-scale rangeland fires to greater sage-grouse habitat and the sage-steppe ecosystem. This study reports the results of using the STARFire planning and budgeting system to respond to Section 7(b) iii-Fuels, Action Item \#4 of the secretarial order. This study demonstrates the capabilities of STARFire to apply the latest science and technology using a risk-based approach to conduct a wildfire risk analysis and improve the targeting of fuels reduction programs on a landscape-scale study across the Northern Great Basin of the United States.

Keywords: economics, fuel treatment, Great Basin, Landscape analysis, risk, sage-grouse, spatial planning, STARFire, U.S. Bureau of Land Management.wildland fire.
\end{abstract}

\section{INTRODUCTION}

The sage-steppe ecosystem is the most widespread in the United States [1]. It is comprised primarily of sagebrush and nearly 60 percent occurs on U.S. Bureau of Land Management (BLM) and U.S. Forest Service federally administered lands in the arid intermountain regions within the western United States. Despite its expanse, the sage-steppe ecosystem is one of the most imperiled in the United States. [2]. Wildfire, invasive annual grasses and conifer expansion threaten the continuity of the ecosystem [3]. This is concerning for managers of sagebrush obligate species such as the endemic greater sage-grouse (Centrocercus urophasianus; hereafter, referred as sage-grouse). In March 2010, the degradation of the sagebrush ecosystem and the resulting impact on the sage-grouse population warranted the United States Fish and Wildlife Service (FWS) to place the sage-grouse on the federal list of candidate species under the Endangered Species Act [3]. A contributing factor in listing the sage-grouse was 'the lack of sufficient regulatory mechanisms' [3] in federal land use plans to address the threats to the sage-grouse and its habitats [4]. Following the 2010 listing, the BLM and Forest Service responded with a new management direction for land use plans that placed greater emphasis on conserving sage-grouse to proactively reverse the trends [4].

In 2014, the DOI identified potential project areas and management strategies to reduce threats to sage-grouse in highly valued sage-grouse habitats [5]. The Northern Great Basin (NGB) Fire and Invasives Assessment Tool (FIAT) identified a series of potential linear fuel and invasive plant treatments in five priority sage-grouse conservation areas identified by the FWS [3]. The FIAT treatment areas were categorized as high, medium and low priority. 
In January 2015, the Rangeland Fire Prevention, Management and Restoration Secretarial Order 3336 (SO3336) was signed by the secretary of the U.S. Department of Interior (DOI). The order directed the creation of a Rangeland Fire Task Force to develop a comprehensive science-based strategy to reduce the threat of large-scale rangeland fires to greater sage grouse habitat and the sage-steppe ecosystem. A final report [6] outlined specific actions required by the task force including Section 7(b) iii-Fuels Action Item \# 4 (the action item) to 'Coordinate the development of effective landscape-level fuels treatments plans' and 'initiate a pilot project to test existing tools and/or prototype versions of new tools [6].' This action item highlights the need to consider economic models that 'describe the cost-effective return on investments [6].'

The FIAT treatments provided important direction but lacked the richness of analysis to guide the efficient allocation of scarce funds. Hence, the BLM initiated a pilot project using the STARFire spatial fire planning and budgeting system. STARFire was developed in collaboration with the DOI's National Park Service (NPS), FWS, and the BLM at the WESTFIRE Research Center at Colorado State University [7]. STARFire integrates fire behavior information, fire affected resource information and management cost information to generate outputs based on return on investment (ROI) to more efficiently allocate scarce fuel treatment budgets.

This application relied on STARFire's Wildfire Risk Assessment and Fuel Treatment analysis modules. The Wildfire Risk Assessment uses fire behavior information to build a custom fire footprint based on conditional probabilities for each ignitable cell on the landscape [8]. Using the fire-affected resource information, the expected net benefit or loss within the footprint is calculated and stored at the ignition cell to quantify the risk and benefit of wildfire on the landscape. STARFire's Fuel Treatment analysis estimates the expected value added from wildfire management activities (for resource protection or ecosystem benefit to habitat) by combining the burn probabilities with the fire-affected resource values across the entire landscape. The burn probability is calculated for each cell using spread and ignition probabilities [9]. The expected value added is combined with the cost information to estimate the expected ROI. The ROI surface is used to optimize and prioritize fuel treatments.

\section{PROJECT OBJECTIVES}

The action item promulgated to project objectives:

1. Generate a wildfire risk analysis that identifies where wildfire is expected to produce the greatest loss to sage-grouse and other fire-affected resources and where fire can generate ecosystem benefit.

2. Inform the strategic location of fuels treatments to aid planners in prioritizing and optimizing fuel treatments that reduce risk to sage-grouse while considering the full spectrum of fire-affected values to maximize ROI under two scenarios:

a. restrict STARFire to prioritize the previously identified FIAT treatments

b. use STARFire without restriction to optimize fuel treatments across the entire conservation area.

\section{METHODS}

The NGB FWS conservation area was selected as a study site to demonstrate the potential utility of STARFire for this kind of application. STARFire's Risk Analysis function was applied to the study area to accomplish project objective one and the Fuel Treatment Optimization and Prioritization Analysis function was applied to address project objective two. 


\subsection{Northern Great Basin study site}

The NGB encompasses 15,732, 000 acres covering four states: Idaho, Oregon, Nevada and Utah and is within seven BLM District Office boundaries. The NGB site is known for its high risk for loss of sage-steppe due to wildfire and invasive plants. The area has a high density of sage-grouse and sage-grouse leks. It has FIAT fuels treatments in place and has planned for sage-grouse habitat restoration and protection. Its size makes it exceptionally large for conducting a singular fuel treatment optimization analysis, making this study the first of its kind to be applied at such scale.

\subsection{STARFire inputs}

The STARFire Wildfire Risk Analysis and the STARFire Fuel Treatment Analysis use three core datasets. The first includes fire behavior information, the second considers the resources affected by fire (both positively and negatively), and the third includes management costs. All geospatial inputs collected for the NGB were converted into raster format. A cell size of $480 \mathrm{~m}$ (approximately 57 acres) was implemented to holistically process the large landscape.

\subsubsection{Fire behavior}

We used FlamMap (v5.0) [10] to estimate flame length (m), heat/unit area (BTU/ft ${ }^{2}$ ), rate of spread $(\mathrm{m} / \mathrm{min})$ and spread direction (degrees) in each raster cell for the STARFire analysis under a 90th percentile weather scenario. Supporting data were supplied by LANDFIRE (v1.3.0) [11] (fuel model, aspect, canopy bulk density, canopy base height, canopy cover, canopy height, elevation and slope) and the BLM provided fire history information including ignition locations and large fire perimeters. STARFire uses fire history information, including ignition locations and large fire perimeters to calculate ignition and burn probabilities.

\subsubsection{Valuation of fire-affected resources}

STARFire requires geospatial data to identify and estimate fire-affected values. Much of these data were incorporated directly from the Greater Sage-Grouse Wildfire, Invasive Annual Grasses, and Conifer Expansion Assessment for the NGB (BLM, 2015). Values to protect included developed areas (infrastructure, developed areas and communities at risk), sagegrouse existence locations with various densities (high breeding bird density (100\%), moderate breeding bird density ( $75 \%$ to $100 \%)$ ), low breeding bird density $(<75 \%))$, conifer encroachment areas (phase $1(<15 \%$ canopy cover), phase $2(15 \%-30 \%$ canopy cover) and phase $3(<30 \%$ canopy cover)), and the location of sagebrush ecosystem with the ability to resist and be resilient to the impacts of invasive annual grasses and altered fire regimes based on the methodologies developed by Chambers et al., [12]. The spatial locations of these fireaffected values are summarized in Fig. 1.

The fire-affected values were estimated using the non-market and non-monetized economic valuation system known as MARS (Marginal Attributes of Substitution) [13]. Rates of substitution between fire-affected resources were estimated through a structured elicitation process of NGB FIAT fire and resource subject matter experts. Relative values also vary by fire intensity and resource condition. Flame height was used as a proxy for establishing RMVs by fire intensity and the amount of time since last fire was used as a proxy for the resource condition. 

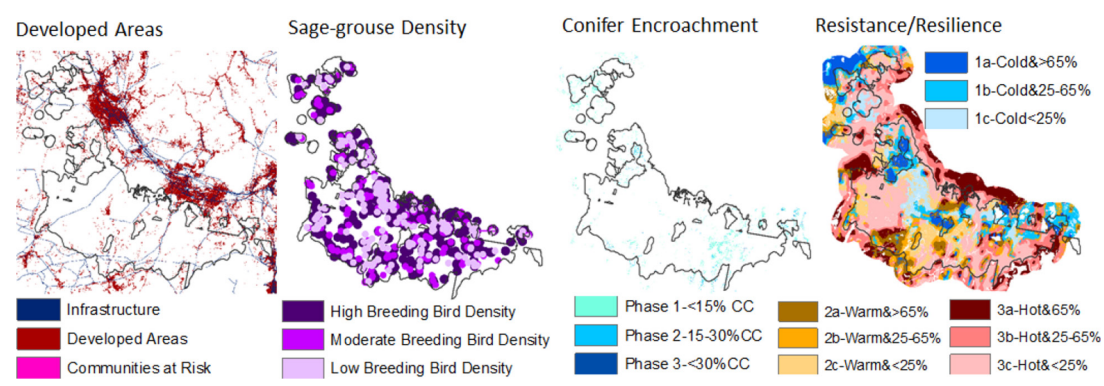

Figure 1: The spatial representation of the NGB FIAT fire affected values. (a) Panel a; developed areas (b) Panel b; sage-grouse, (c) Panel c; conifer encroachment based on canopy cover and (d) Panel d; the sage grouse resistance/resilience model.

\subsubsection{Management costs}

Including the cost of fuels treatments is essential to locating fuels treatments that will maximize the ROI and make the best use of the budget. Cost drivers included distance from road, vegetation type (grass-like, shrub-like, tree-like) and time since last fire. If the resource had experienced fire within the 'years since last fire breakpoint' (defined in 3.1.1), it was included in the 'has experienced fire' cost category, otherwise it was included in the 'has not experienced fire' category (Table 1). The distance from road cost driver was divided into ' $<2$ miles from road' and '>2 miles from road' categories. This was based on BLM data indicating that costs for treatments are higher on average if a treatment is located or extends greater than two miles from a road or access point. Cost coefficients were then estimated using historical contracting averages as summarized in Table 1.

\subsection{STARFire analysis}

STARFire's Wildfire Risk Assessment (objective 1) and STARFire's Fuel Treatment analysis (objective $2 \mathrm{a}$ and $2 \mathrm{~b}$ ) were conducted on the NGB landscape. The risk assessment provided a preliminary validation of the system inputs and was collaboratively verified with BLM team members. The fuel treatment analysis was conducted under two scenarios. First, STARFire's fuel treatment prioritization was restricted to the proposed NGB FIAT treatment areas (objective 2a). Here, the proposed NGB FIAT treatment areas were provided by the BLM as shapefiles. The second was unrestricted and allowed treatments across the NGB landscape (objective 2b).

The shapefiles were converted to rasters with the same resolution as the input data $(480 \mathrm{~m})$. The number of acres that comprised each priority level within the proposed fuel treatments

Table 1: Relative fuel treatment costs.

\begin{tabular}{lllll}
\hline & $\begin{array}{l}\text { Has experienced } \\
\text { fire \& < miles } \\
\text { from road }\end{array}$ & $\begin{array}{l}\text { Has not experi- } \\
\text { enced fire \& <2 } \\
\text { miles from road }\end{array}$ & $\begin{array}{l}\text { Has experienced } \\
\text { fire \& }>\mathbf{2} \text { miles } \\
\text { from road }\end{array}$ & $\begin{array}{l}\text { Has not experi- } \\
\text { enced fire \& > 2 } \\
\text { miles from road }\end{array}$ \\
\hline Grass-like & 1 & 5 & 2.3 & 11.67 \\
Shrub-like & 3 & 7 & 7 & 16.33 \\
Tree-like & 9 & 18 & 21 & 42 \\
\hline
\end{tabular}


were re-calculated to account for the new resolution. The total re-sampled NGB FIAT treatment area (1,231,056 acres) contained 554,493 high-priority acres, 296,304 moderate-priority acres and 380,259 low-priority acres. In the first scenario, three STARFire treatment levels were run corresponding with each FIAT priority acre budget. In that analysis, we were allowed to treat outside a priority area but were restricted to the combined area of the FIAT treatments. In the second scenario, fuel treatment was unrestricted and treatment areas were selected based on the total resampled acre budget (1,231,056 acres). Recent fires (areas that have burned in five years or less) were excluded from the analysis.

\section{RESULTS}

Results of the STARFire analysis are discussed for the risk assessment and for the two fuel treatment scenarios.

\subsection{Wildfire risk assessment (Objective 1)}

A STARFire Wildfire Risk Assessment was generated for the NGB landscape (Fig. 2., panel a). It depicts the expected value of wildfire impact for any cell igniting on the landscape. Green areas indicate cells that would produce a positive expected outcome if burned and red cells indicate a negative or detrimental expected outcome to sage-grouse and other affected resources. Darker colors indicate greater impacts. The Wildfire Risk Analysis shows that most of the NGB landscape is at risk from wildfire.

4.2 Inform the strategic location of fuels treatments to achieve the least loss to sage-grouse habitat (Objective 2)

The STARFire Fuel Treatment analysis was generated for the NGB landscape to create an ROI surface (Fig. 2. Panel b). Areas that are darker in color represent areas on the landscape that would generate a higher ROI from fuel treatment.
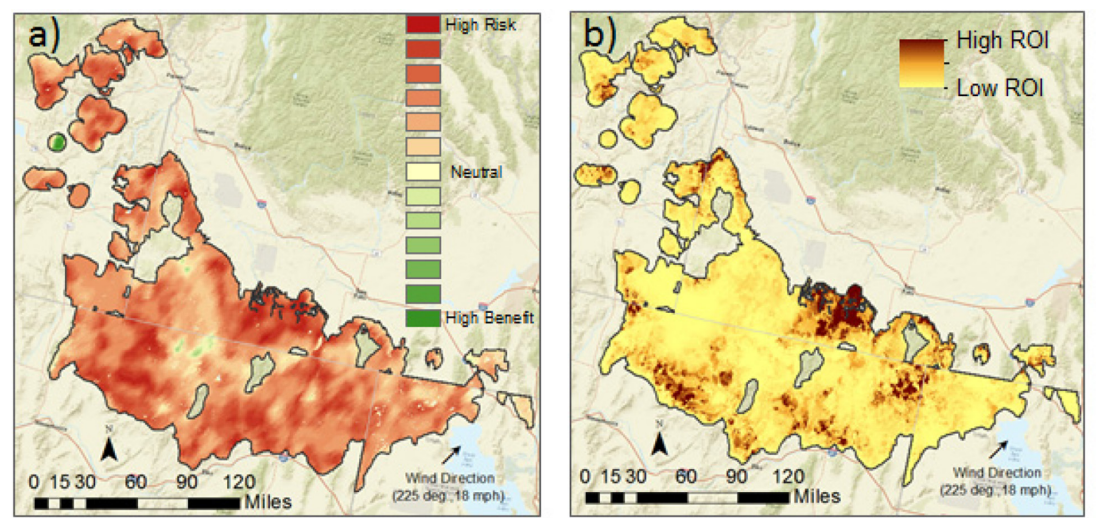

Figure 2: (a) Panel a; Wildfire Risk -- areas in red represent high risk of loss from wildfire and areas in green provide ecosystem benefit if burned. (b) Panel b; return on investment (ROI) at the NGB. Darker colors represent areas that would generate a higher ROI from fuel treatment. 
4.2.1 Prioritizing the proposed NGB FIAT treatments (Objective 2a)

The results of STARFire's prioritization of the proposed NGB FIAT treatments (high, moderate and low) are shown in Fig. 3. The figure compares the proposed NGB FIAT treatments for each priority level (Panel a) to the STARFire prioritized locations for the same acre budget based on the ROI surface and restricted to NGB FIAT area (Panel b). The STARFire fuel treatment locations are then further prioritized within the priority level in Panel c.

Some of the STARFire treatment priorities are similar to those selected by the NGB FIAT assessment (Fig. 4., box b) while others differ as shown in the NGB FIAT (Fig. 4., box a). In this area, the proposed NGB FIAT priority is moderate and the STARFire treatment priority is low.

A source of the difference is due to the underlying inputs (fire-affected resources, management costs and burn potential) and is displayed in box a). The only fire-affected resource represented in this area is warm soils (class 2a and 2b) (Fig. 5., Panel a., image ii). A small amount of moderate sage-grouse breeding bird density (Fig. 5., Panel a., image i) is represented and there is minimal conifer encroachment (Fig 5., Panel a., image iii). The area is
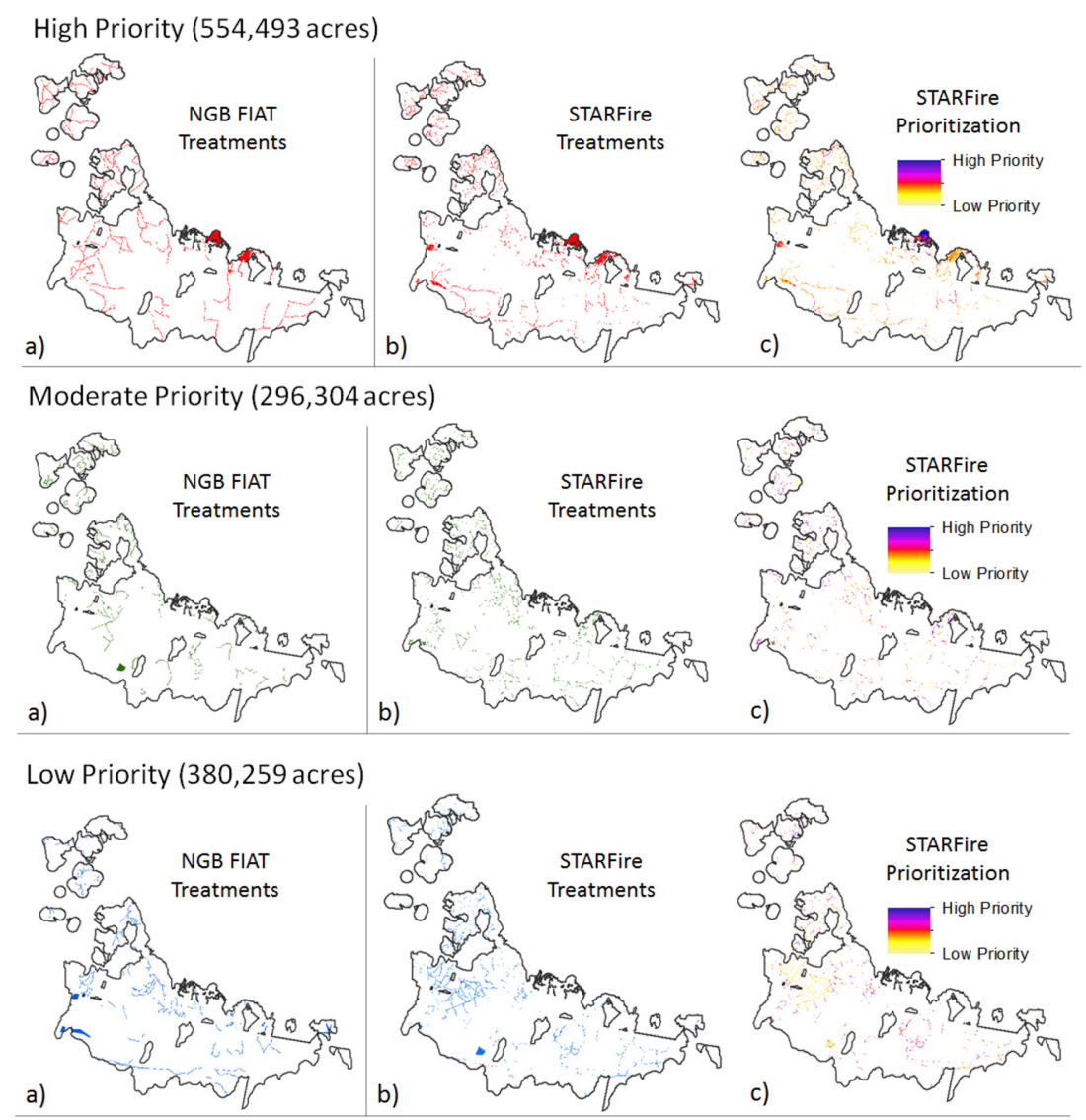

Figure 3: Comparison of the fuel treatment selections of the proposed NGB FIAT locations and STARFire selections based on ROI and the number of acres in each priority level. 

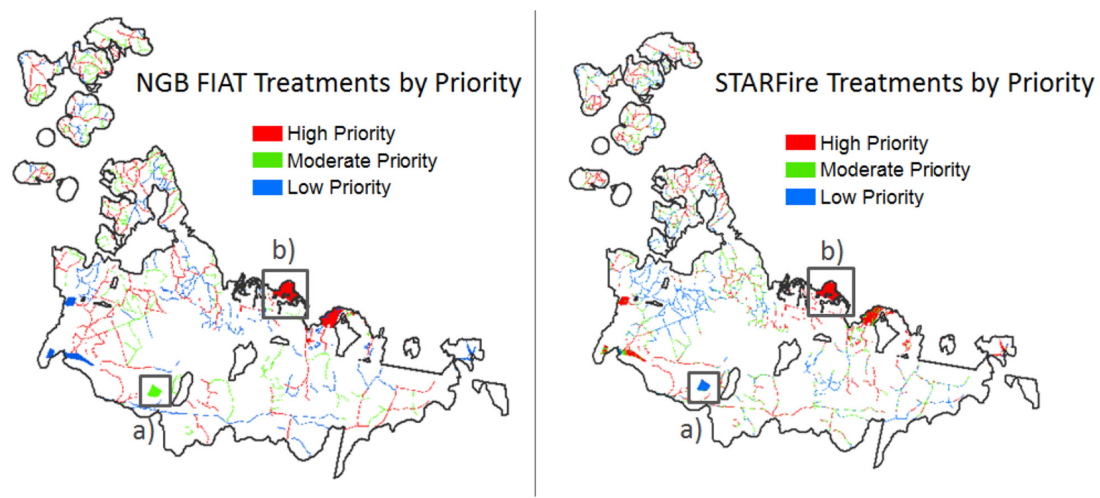

Figure 4: Comparison of NGB FIAT treatment priorities and STARFire treatment priorities. Box a) represents areas where the priorities differ and box b) represents an area where the priorities are similar.
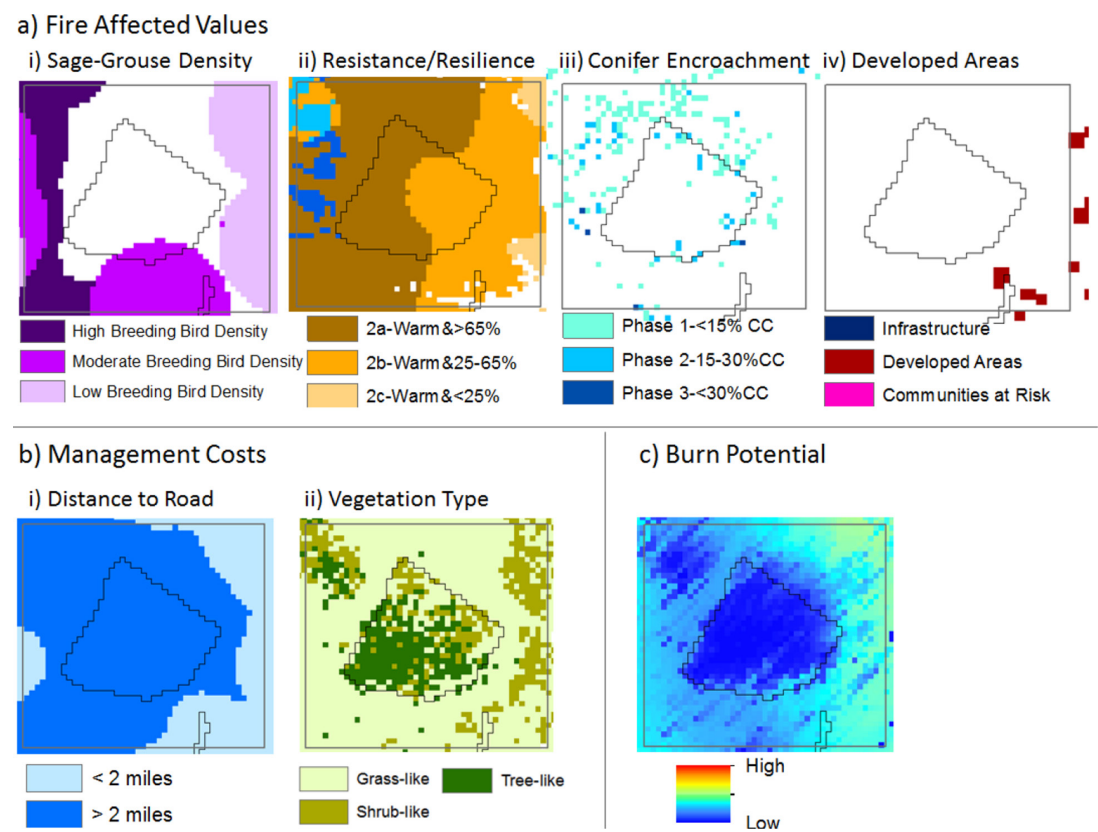

c) Burn Potential

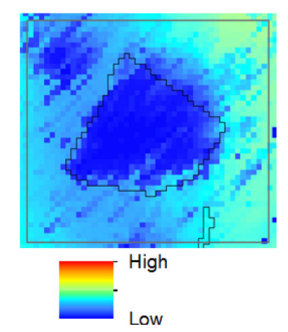

Figure 5: STARFire inputs in part of the landscape. (a) Panel a; the fire-affected values, (b) Panel b; fuel treatment costs and (c) Panel c; the burn probability.

void of developed areas (Fig 5., Panel a., image iv). While the associated fire loss for the warm soils is high, the collective value of fire-affected resources in this area is much lower than other areas on the landscape that contain multiple resources on the same cells. The management cost input layer (Fig. 5., Panel b) contains an area located more than two miles from a road and covered with tree-like vegetation for most of the area. This area is likely covered by natural conifer. Both factors contribute to a high treatment cost (Table 1). As the final input, burn potential in this area reveals that it has a low probability of burning (Fig. 5., 
Panel c.). After combining all factors together, STARFire suggested that this area should have a lower priority for treatment in comparison to other areas on the landscape.

\subsubsection{Optimizing treatments on the entire NGB landscape (Objective 2b)}

STARFire fuel treatments were optimized across the entire NGB landscape under the resampled NGB FIAT acre budget (1,231,056 acres). In Fig. 6, the treatment locations identified by the proposed NGB FIAT assessment are overlaid on the STARFire fuel treatment locations for comparison. Areas contained by box a) and box b) in Fig. 6 have similar treatment priorities between the STARFire results and the NGB FIAT assessment. The NGB FIAT assessment also proposed numerous fuel breaks in the area contained in box c). However, the STARFire analysis focused less in this area due to low burn probabilities.

The treatment budget $(1,231,056$ acres $)$ is also summarized by high ROI treatment values for each of the states in the NGB FIAT (Fig. 7). High ROI treatment acres represent an acre-equivalent budget to the high prioritiy treatment acres in the NGB FIAT treatment $(612,314$ acres) that produce the top 50\% of ROI. In Fig. 7, Panel a) the top 50\% of ROI was summed across the NGB to show where the highest ROI acres are by state. This is influenced by how many acres each state has in the NGB. Idaho contains the highest number of high ROI treatment acres, followed by Neveda, Oregon and Utah. Fig. 7, Panel b) shows the number of high ROI acres divided by the number of treatable acres in a particualr state. This Panel $b$ shows that Idaho has a much higher proportion of high ROI acres per treatable acres in the NGB in comparison to Nevada, Oregon or Utah.

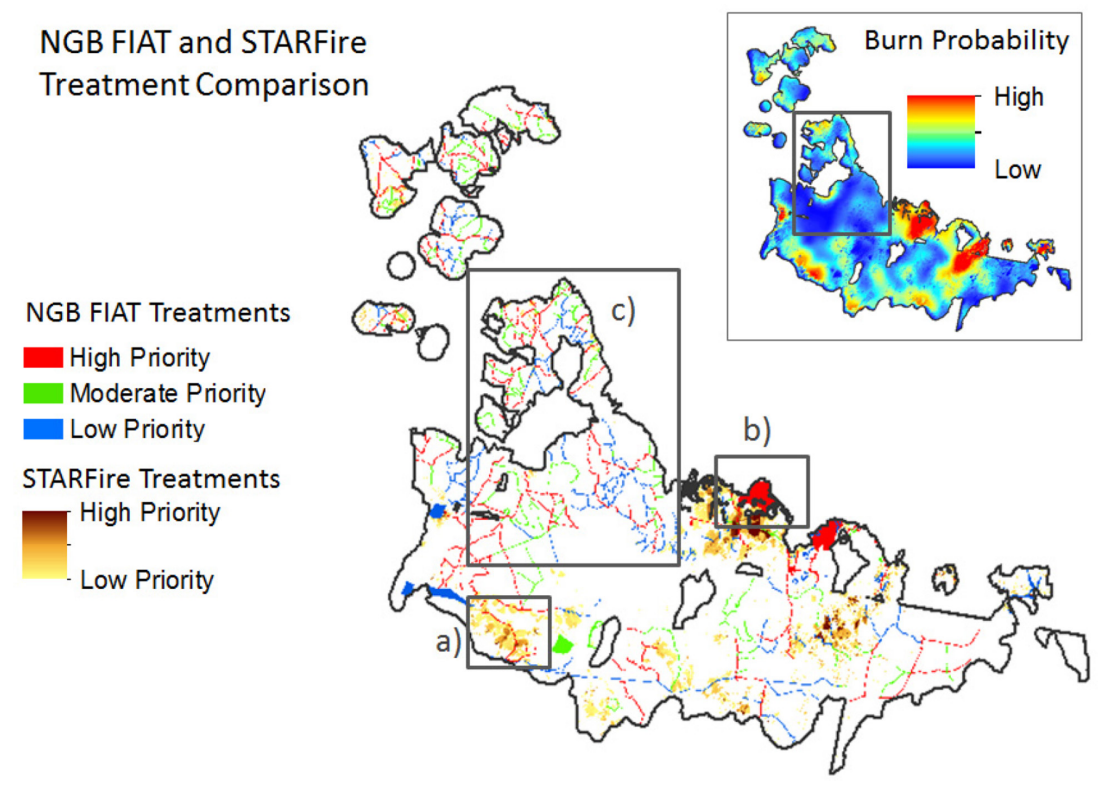

Figure 6: Comparison of proposed NGB FIAT fuel treatments to STARFire fuel treatments for a 1,231,056 acre budget. Box a) and box b) identify similar treatment priorities. Box c) identifies an area where the NGB FIAT recommends treatments and STARFire does not. When assessing the STARFire inputs, the biggest factor contributing to this difference is the burn probabilities for this region. 

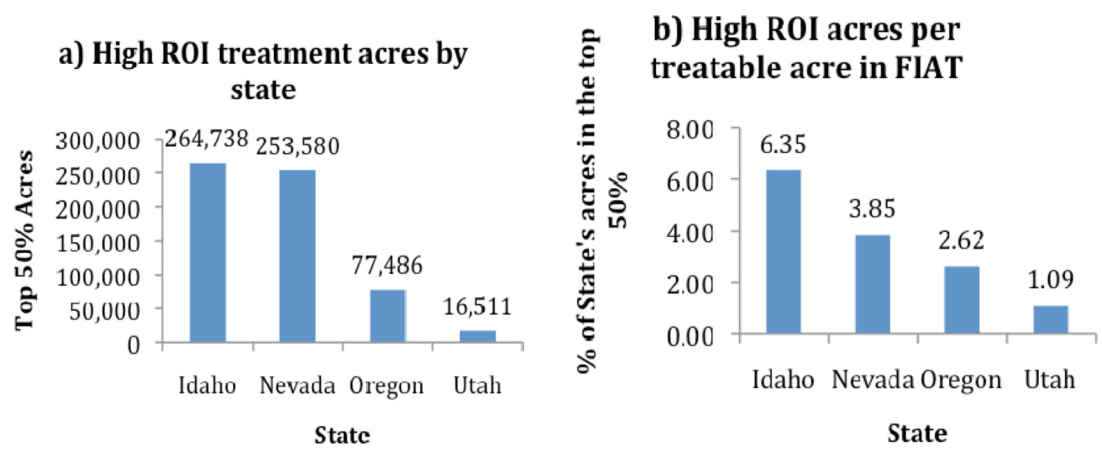

Figure 7: (a) Panel a; summarizes the high ROI acres by state and (b) Panel b; shows the proportion of each state's acres that have high ROI.

\section{CONCLUSIONS}

In 2015, the DOI issued Secretarial Order 3336 directing the development of a comprehensive science-based strategy to reduce the threat of large-scale rangeland fires to greater sage grouse habitat and the sage-steppe ecosystem. The greater sage-grouse problem is central to issues of sustainable development in that the potential for its listing as an endangered species may have significant implications for land use and development. This study demonstrates the capabilities of STARFire to apply the latest science and technology using a risk-based approach to generate a wildfire risk analysis and to improve the targeting of fuels reduction opportunities on a landscape-scale study across the Northern Great Basin. This pilot study represents the first time that a spatial planning system has processed a risk analysis and located potential fuel treatments at a large scale of approximately 16 million acres as one. The sage grouse problem is several times larger than the 16 million acre pilot study reported here. The system provided land managers the ability to combine resource value, cost and fire behavior information with considerations regarding the prioritization of fuel treatments. By comparing between fuel treatment prioritization from the NGB FIAT assessment and those selected by STARFire, land managers can improve their decision accuracy. Including management costs permits land managers to use ROI to support decisions. The wildfire risk analysis can aid managers in their assessment of the appropriate response to wildfire across the landscape and inform adaptive management after a large fire. While the pilot project demonstrated promise by addressing the challenges identified by the DOI, certain modifications could improve its accuracy and reliability. These include reviewing the value set. Given that a problem of this magnitude represented uncharted territory, we used a relative large cell size for demonstration purposes in the pilot study. Reducing the cell size may also help improve accuracy

\section{REFERENCES}

[1] USFWS. Why Care About America's Sagebrush? US Fish and Wildlife Service, Denver, Colorado. February 2014, available at https://www.fws.gov/ mountain-prairie/ factsheets/Sage-steppe_022814.pdf. (accessed 15 December 2016).

[2] Welch, B.L., Big sagebrush: a sea fragmented into lakes, ponds, and puddles. Vol. General Technical Report RMRS-GTR-144: U. S. Department of Agriculture Forest Service, Rocky Mountain Research Station, 2005. 
[3] U.S. Fish and Wildlife Service. Greater Sage-grouse (Centrocercus urophasianus) Conservation Objectives: Final Report. U.S. Fish and Wildlife Service, Denver, CO. February 2013.

[4] Finch, D., Boyce, D., Chambers, J., Colt, C., McCarthy, C., Kitchen, S., Richardson, B., Rowland, M., Rumble, Schwartz, M. Tomosy, M. Wisdom. 2015. USDA Forest Service Sage-Grouse Conservation Science Strategy 2015-2020. USDA Forest Service. Washington, DC.

[5] DOI. Greater Sage-Grouse Wildfire, Invasive Annual Grasses \& Conifer Expansion Assessment (Fire and Invasive Assessment Tool (FIAT)). Central Oregon. June 2015. Prepared by Fire and Invasive Assessment Team (Appendix 5), P. 43, 2015.

[6] BLM. An Integrated Rangeland Fire Management Strategy, Final Report to the Secretary of the Interior, p. 82, May 2015.

[7] Rideout, D., Wei, Y., Kirsch, A. \& Kernohan N. (In Press). STARFire: Strategic budgeting and planning for wildland fire management. Park Science, 32(3).

[8] Rideout, D., Wei, Y., Kirsch, A. \& Botti, S. Toward a unified economic theory of fire program analysis with strategies for empirical modelling. In The Economics of Forest Disturbances: Wildfires, Storms and Invasive Species, eds T.P. Holmes, J.P. Prestemon \& K.L. Abt, Springer: New York, pp. 361-380, 2008. https://doi.org/10.1007/978-1-4020-4370-3_18

[9] Rideout, D.B. \& Kernohan N. The relative value of fire planning alternatives. In Modelling, Monitoring and Management of Forest Fires III, eds C.A Brebbia \& G. Perona, WIT Press: Boston, MA, pp. 151-162, 2012. https://doi.org/10.2495/FIVA120131

[10] FLAMMAP. 2016, available at https://www.firelab.org/flammap, (accessed January, 2015).

[11] LANDFIRE. 2016, available at http://www.landfire.gov. (accessed December, 2015).

[12] Chambers, et al., Using resistance and resilience concepts to reduce impacts of invasive annual grasses and altered fire regimes on the sagebrush ecosystem and greater sagegrouse: A strategic multi-scale approach. Gen. Tech. Rep. RMRS-GTR-326. Fort Collins, CO: U.S. Department of Agriculture, Forest Service, Rocky Mountain Research Station. p. 73, 2014.

[13] Rideout, D.B., Ziesler, P.S., Kling, R., Loomis, J.B. \& Botti, S.J., Estimating rates of substitution for protecting values at risk for initial attack planning and budgeting. Forest Policy and Economics, 10, pp. 205-219, 2008.

https://doi.org/10.1016/j.forpol.2007.10.003 